\title{
RESEARCH
}

Open Access

\section{Off-label and unlicensed drug use in Ayder comprehensive specialized hospital neonatal intensive care unit}

Meles Tekie Gidey ${ }^{1 *}$ D, Yohannes Gebrehaweria Gebretsadkan', Afewerki Gebremeskel Tsadik², Abraham Gebrezgabiher Welie ${ }^{1}$ and Brhane Teklebrhan Assefa ${ }^{3}$

\begin{abstract}
Background: Off- label drug use refers to the use of medicines outside of their marketing authorization with respect to dose, dosage form, route of administration, indication or age. Off-label/unlicensed drug use significantly associated with adverse drug reactions and medication errors in neonates and critically ill neonates are more vulnerable to these problems.

Objective: To assess the prevalence and associated factors with off-label and unlicensed drug use in neonatal intensive care unit of Ayder Comprehensive Specialized Hospital.

Methods: A cross-sectional study was conducted from March 01,2019 to April 30, 2019 in neonatal intensive care unit of Ayder Comprehensive Specialized Hospital. Neonates admitted for $24 \mathrm{~h}$ and took at least one medicine were included in the study. Data was collected from prescription and medical charts. The off-label and license status of the medicine was verified based on European medicine Agency electronic medicine compendium. Data was analyzed by SPSS version 21.0. Binary and multivariate logistic regression was done to assess the predictors of offlabel/unlicensed medicine use at $p$-value $\leq 0.05$ significance level.

Result: A total of 364 medicines prescribed for 122 neonates were analyzed. The prevalence of off-label and unlicensed drug use was 246 (67.58\%), and 86 (23.63\%) respectively. Of the total 122 neonates, 114(93.44\%), and $57(46.72 \%)$ of them were exposed to at least one off-label and unlicensed drug respectively. Antibiotics were the most commonly prescribed off-label and unlicensed drugs. No statistically significant association was found between demographic as well as health related variables with off-label/unlicensed medicine use at $p$-value of $\leq 0.05$ significance level.
\end{abstract}

Conclusion: Off-label and unlicensed medicine use was high among neonates admitted to intensive care unit of the hospital. Selecting the safest medicines for such vulnerable patients is crucial to promote rational prescribing and better therapeutic benefit.

Keywords: Off-label use, Unlicensed use, Drug-use, Neonate, Intensive care unit

\footnotetext{
*Correspondence: melestekie@gmail.com; meles.tekie@mu.edu.et

${ }^{1}$ Pharmacoepidemiology and Social pharmacy Course and Research Unit,

School of Pharmacy, College of Health Sciences, Mekelle University, Mekelle,

Ethiopia

Full list of author information is available at the end of the article
}

(c) The Author(s). 2020 Open Access This article is licensed under a Creative Commons Attribution 4.0 International License, which permits use, sharing, adaptation, distribution and reproduction in any medium or format, as long as you give appropriate credit to the original author(s) and the source, provide a link to the Creative Commons licence, and indicate if changes were made. The images or other third party material in this article are included in the article's Creative Commons licence, unless indicated otherwise in a credit line to the material. If material is not included in the article's Creative Commons licence and your intended use is not permitted by statutory regulation or exceeds the permitted use, you will need to obtain permission directly from the copyright holder. To view a copy of this licence, visit http://creativecommons.org/licenses/by/4.0/. The Creative Commons Public Domain Dedication waiver (http://creativecommons.org/publicdomain/zero/1.0/) applies to the data made available in this article, unless otherwise stated in a credit line to the data. 


\section{Background}

Two-thirds of the medicines used to treat pediatric patients do not have appropriate information regarding their safety and efficacy for use in these population. Pediatric patients are treated with medicines that are not tested for safety and efficacy or their uses are frequently supported by low quality of evidence for safety and efficacy $[1,2]$. The situation is worse when the patients are neonates, due to their unique physiology where the pharmacokinetic evidence of medicines in older patients cannot be extrapolated [3]. Therefore, in the absence of standard prescribing information about the medicine, clinicians might be forced to prescribe medicines in unlicensed or off-label manner $[2,4]$.

Off- label medicine use refers to the use of medicines outside of their marketing authorization (product license) with respect to dose, dosage form, route of administration, indication or age [2,3]. Unlicensed use refers to a medicine that does not have a marketing authorization (not authorized and licensed in a country), does not have suitable formulation in the market or extemporaneously prepared products (i.e. modified administration of licensed products) [3, 5-8]. Off-label and unlicensed medicine use is not necessarily incorrect and has to be considered when there is no other option, but it does cause risks and complications to the patient's condition $[3,9]$.

Off-label and unlicensed medicine use in the newborn increases the risk of adverse drug reaction (ADR), medication errors and misuse [3, 10]. According to a literature review by Cuzollin in 2014, the risk of ADRs due to off-label/unlicensed drug use in pediatric population comprised of neonates is reported to be in the range of 23 to $60 \%$, indicating the association of off-label/ unlicensed drug use with increased risk of ADRs. Offlabel/unlicensed medicine use also found to be significantly associated with increased risk of medication errors in neonatal intensive care unit (NICU), up to 8 times greater than in other departments [7].

Despite the increased risk of medication error and ADRs, the incidence of off-label/unlicensed medicine is highest among neonates admitted to NICU. For instance many studies reported off-label/unlicensed drug exposure in NICU patients in the range of 38 to $99.5 \%$ [3, 9, $11-14]$ and $1.9 \%$ up to $24 \%[3,11,14-16]$ respectively.

Little is known about the use of off-label/unlicensed medicine among NICU patients in Ethiopia. A crosssectional study from University of Gondar reported that $75 \%$ of the prescribed medicines for pediatric patients were off-label [17]. The problem might be worst among neonates where the availability of maternal and child health medicines is very low [18] and due to the challenges of getting approved suitable medicine formulations for these patient groups. Considering the concerns of increased risk of ADRs and medication errors with off-label/unlicensed medicine use, it is imperative to assess the status of their use among NICU patients to have base line evidence. Therefore, the objective of this study was to assess the prevalence and factors associated with off-label and unlicensed drug use among neonates admitted to the NICU of Ayder Comprehensive Specialized Hospital (ACSH), a teaching hospital in Mekelle university, Mekelle, Ethiopia.

\section{Methods}

\section{Description of the study design}

This cross-sectional study was conducted in NICU of ACSH, Mekelle city, Northern Ethiopia. All medicines prescribed to neonates admitted to the NICU of the hospital from March 01,2019 to April 30, 2019 were assessed for their off-label and license status.

Neonates (age 0-28 days) admitted at NICU for at least $24 \mathrm{~h}$ and have been prescribed at least one medication to treat their medical condition, were included in the study. Neonates maintained only on oxygen therapy, parenteral nutrition, blood products, antiseptics, vaccines and intravenous fluid such as normal saline and dextrose and those having incomplete information in their medical chart/prescription were excluded from the study.

\section{Data collectors and data collection procedure}

The data was collected from medical chart and prescriptions by a trained data collector using a structured data collection form. The data collection form includes the patients demographic details: diagnosis, NICU stay, treatment outcome and drug related data such as the number of prescribed medicine, the medicines brand/ generic name, category of the medicine, dose, dosage form, route of administration, dosing frequency and indication. Neonates were categorized into three groups pre-term neonates ( $\leq 36$ weeks gestational age) term neonates (37-39 weeks gestational age) and post-term neonates ( $\geq 40$ weeks gestational age) [19].

The prescribed medicines were classified into three categories; off-label, unlicensed and licensed based on the European Medicine Agency electronic medicine compendium. For the purpose of this study, off-label medicine use is defined as the administration of a drug in a different manner from the recommended one in the marketing authorization with regard to age, dose, dosing frequency, administration route, or indication. Similarly licensed medicines are medicines which were prescribed and administered, following the terms of their marketing authorization. Unlicensed use refers to a medicine that does not have a marketing authorization (has no authorization license in a country), does not have suitable formulation in the market or it is extemporaneously 
prepared product (i.e. modified administration of licensed products).

\section{Statistical analysis}

The collected data was checked and cleaned for consistency by an independent third party on daily basis. The data then was entered and analysed by using SPSS Version 21.0. Frequencies and percentages were calculated for all variables which were related to the objectives of the study. Binary logistic regression analysis was computed to assess the association of demographic/ health related variables with off-label/unlicensed drug use at $95 \% \mathrm{CI}$ and $p$-value $\leq 0.05$ significance level.

\section{Ethical considerations}

Ethical clearance was obtained from ethical review board of School of Pharmacy, College of Health Sciences, Mekelle University. The study was conducted after getting official permission from the hospital administration.

\section{Results}

\section{Demographic and health related characteristics of the} study population

A total of 133 neonates were admitted to the NICU during the study period and 122 of them were included into the study and the rest was excluded due to incomplete information. Of the 122 participants, male preponderance $72(59 \%)$ was seen, and (56.6\%) were term neonates. The mean age of the neonates was 1 day, majority (91\%) of them being under the age of 7 days. The mean number of hospitalization stays was $6.41 \pm 5.98$ days (ranging from 1 to 32 days) with a total of 307 days of hospitalization for all the neonates. The neonates have been prescribed an average of $3.02 \pm 1.40$ medicines per prescription. The most common admission diagnosis was early onset neonatal sepsis 63(51.6\%), accompanied by, respiratory distress syndrome $13(10.7 \%)$ and late onset neonatal sepsis 6(4.9\%). (Table 1 describes the demographic and health related details).

\section{Off-label and unlicensed medicine use}

From the total of 122 neonates included in the study 114 (93.44\%) of them were exposed to at least one offlabel medicines. In addition, 57 (46.72\%) of them were exposed to at least one unlicensed medicines. Considering the total number of medicines prescribed to the neonates $(n=364)$, the prevalence of off-label and unlicensed medicines prescriptions were 246 (67.58\%) and $86(23.63 \%)$ respectively (Fig. 1 ).

Prescriptions containing at least one off-label medicine were relatively higher among post-term (8/8) and preterm (43/45) neonates (Table 2).

The most widely prescribed off-label medicines categories in NICU were antibiotics $(187,51.38 \%)$ followed
Table 1 Demographic and health related detail of neonates in ACSH, NICU, April $2019(n=122)$

\begin{tabular}{|c|c|}
\hline Variables & Frequency (\%) \\
\hline \multicolumn{2}{|l|}{ Gender } \\
\hline Male & $72(59 \%)$ \\
\hline Female & $50(41 \%)$ \\
\hline \multicolumn{2}{|l|}{ Residence } \\
\hline Rural & 49 (40.2\%) \\
\hline Urban & $73(59.8 \%)$ \\
\hline \multicolumn{2}{|l|}{ Gestational age at birth } \\
\hline Pre-Term & $45(36.9 \%)$ \\
\hline Term & 69 (56.6\%) \\
\hline Post Term & $8(6.6 \%)$ \\
\hline \multicolumn{2}{|l|}{ Age category } \\
\hline$\leq 7$ days & $111(91 \%)$ \\
\hline $8-14$ & $11(9 \%)$ \\
\hline Median age & 1 day \\
\hline \multicolumn{2}{|l|}{ Weight (kg) } \\
\hline Mean \pm SD & $2.54 \pm 0.79$ \\
\hline \multicolumn{2}{|l|}{ Hospital NICU stay(day) } \\
\hline$\leq 7$ & 95 (77.86\%) \\
\hline $8-14$ & $14(11.48 \%)$ \\
\hline$\geq 15$ & $13(10.66 \%)$ \\
\hline Mean $\pm(S D)$ & $6.41 \pm 5.98$ days \\
\hline \multicolumn{2}{|l|}{ No. medicine per prescription } \\
\hline$\leq 2$ & $64(52.5 \%)$ \\
\hline $3-5$ & $50(41 \%)$ \\
\hline$\geq 5$ & $8(6.5 \%)$ \\
\hline \multicolumn{2}{|l|}{ Admission Diagnosis } \\
\hline Early onset neonatal sepsis & $63(51.6 \%)$ \\
\hline Respiratory distress syndrome & $13(10.7 \%)$ \\
\hline Late onset neonatal sepsis & $6(4.9 \%)$ \\
\hline Others & $40(32.8 \%)$ \\
\hline
\end{tabular}

by Non-steroidal anti-inflammatory agent (NSAID) (17, $4.67 \%)$ and medicines prescribed for seizure $(15,4.12 \%)$. Similarly, antibiotics were also the most commonly prescribed among the unlicensed medicines (31, 8.52\%) (Table 3).

The most commonly prescribed off-label medicine was ampicillin 99(27.2\%) followed by Vancomycin 23(6.33\%) and Ceftazidim 21(91.3\%). Lack of neonatal use information's, and higher dose than the recommended were the main reasons for the off-label use. Paracetamol, phenobarbital, and aminophylline were the most commonly used unlicensed medicines. Similarly, lack of information regarding neonatal use and inappropriate dosage form were the reasons for unlicensed use (Table 4). 


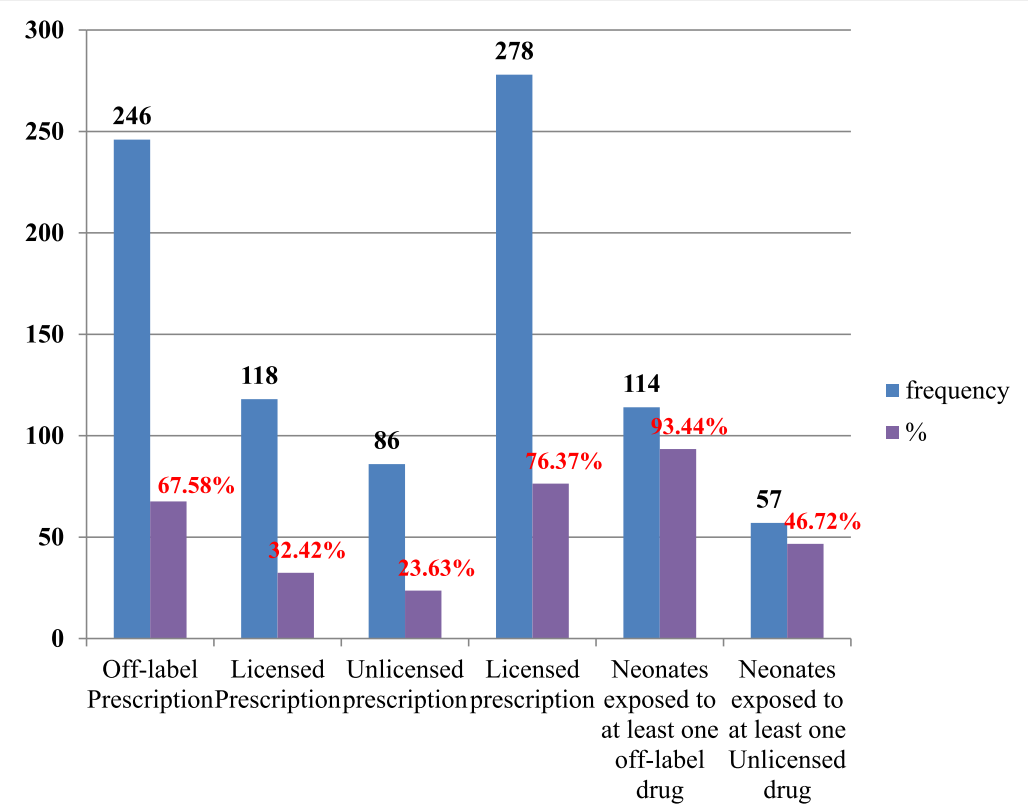

Fig. 1 Magnitude of off-label and unlicensed drug in ACSH NICU, April 2019

On binary logistic regression analysis there was no statistically significant association between demographic/ health related variables and off-label/unlicensed medicine use at $p$-value $<0.05$ significance level.

\section{Discussion}

This study evaluated 364 medicines prescribed for 122 neonates for their off-label and license/authorization status.

Accordingly, the overall off-label medicine use in ACSH NICU was found to be $67.58 \%$. This was higher compared to several study findings elsewhere in the globe which reported off-label medicine use in the range of 23 to $62 \%$ [3, 4, 9, 11, 13, 14, 20-23]. However, it was slightly lower compared to a study from India which reported an off-label prescription of 70\% [2]. The differences might be attributed by the differences in availability of medicines approved for neonatal use, study

Table 2 Off-label and unlicensed drug use by gestational age in ACSH NICU, April 2019 ( $n=122)$

\begin{tabular}{llll}
\hline $\begin{array}{l}\text { Gestational } \\
\text { age }\end{array}$ & Frequency & $\begin{array}{l}\text { Frequency(\%) of } \\
\text { neonates exposed } \\
\text { to at least one off- } \\
\text { label drug }\end{array}$ & $\begin{array}{l}\text { Frequency(\%) of } \\
\text { neonates exposed } \\
\text { to at least one } \\
\text { unlicensed drug }\end{array}$ \\
\hline Term & 69 & $\mathbf{6 3 ( 9 1 . 3 0 \% ) ^ { a }}$ & $30(43.50 \%)^{a}$ \\
Pre-term & 45 & $43(95.55 \%)^{a}$ & $22(48.90 \%)^{a}$ \\
Post-term & 8 & $8(100 \%)^{a}$ & $5(62.5 \%)^{a}$ \\
Over all $^{\text {b }}$ & $\mathbf{1 2 2}$ & $\mathbf{1 1 4 ( 9 3 . 4 4 \% )}$ & $\mathbf{5 7 ( 4 6 . 7 2 \% )}$ \\
\hline
\end{tabular}

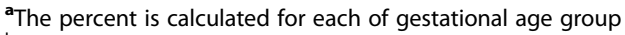

${ }^{b}$ Indicates the overall off-label and unlicensed drug use for $n=122$ design, samples size or differences pediatric medicine use policy.

In this study, high number of neonates were found to be exposed to off-label and unlicensed medicines. Of the total number of neonates included in this study $93.4 \%$ of them were exposed to at least one offlabel medicine prescription. This is slightly higher compared to studies conducted in Germany, Ireland and Iran which reported 69.7-89.9\% [3, 9, 11]. But, this was slightly lower compared to other studies which reported 95.5-99.5\% exposure to off-label medicines [12-14]. This can be due to lack of evidence on safety and efficacy of the medicines for neonatal use due to their limited data from premarketing studies. As a result the health care providers might be forced to prescribe off-label medicines due to lack of options.

Table 3 Off-label and unlicensed drug use by medicines category in ACSH NICU, April $2019(n=364)$

\begin{tabular}{llll}
\hline Drug class & $\begin{array}{l}\text { No .of } \\
\text { prescribed } \\
\text { medicine }\end{array}$ & $\begin{array}{l}\text { Off-label use } \\
\text { Frequency (\%) }\end{array}$ & $\begin{array}{l}\text { Unlicensed use } \\
\text { Frequency (\%) }\end{array}$ \\
\hline Antibiotics & 298 & $187(51.38 \%)$ & $31(8.52 \%)$ \\
NSAIDs & 17 & $17(4.67 \%)$ & $17((4.67 \%))$ \\
Anti-epileptics & 15 & $15(4.12 \%)$ & $15(4.12 \%)$ \\
Vitamins and Minerals & 12 & $10(2.75 \%)$ & $6(1.66 \%)$ \\
Diuretics & 7 & $7(1.92 \%)$ & $7(1.92 \%)$ \\
Respiratory Drugs & 7 & $7(1.92 \%)$ & $7(1.92 \%)$ \\
Others & 8 & $3(0.82 \%)$ & $3(0.82 \%)$ \\
Total & 364 & $246(67.58 \%)$ & $86(23.63 \%)$ \\
\hline
\end{tabular}


Table 4 Most common off-label and unlicensed medicines prescribed in ACSH NICU, April 2019

\begin{tabular}{|c|c|c|c|c|c|}
\hline Drug & $\begin{array}{l}\text { Total medicines } \\
\text { prescribed }\end{array}$ & $\begin{array}{l}\text { Frequency(\%) of } \\
\text { off-label use }\end{array}$ & Reason for off-label use & $\begin{array}{l}\text { Frequency(\%) of } \\
\text { unlicensed use }\end{array}$ & $\begin{array}{l}\text { Reason for unlicensed } \\
\text { use }\end{array}$ \\
\hline Ampicillin & 113 & $99(27.2 \%)$ & Dose too high & & \\
\hline Vancomycin & 23 & $23(6.32 \%)$ & Dose too high & $23(6.3 \%)$ & $\begin{array}{l}\text { Lack of suitable dosage } \\
\text { form }\end{array}$ \\
\hline Ceftazidim & 23 & $21(5.77 \%)$ & $\begin{array}{l}\text { Dose too high and in } \\
\text { appropriate frequency }\end{array}$ & & \\
\hline Ceftriaxone & 18 & $16(4.4 \%)$ & Dose too high & & \\
\hline Paracetamol suppository & 14 & $14(3.85 \%)$ & $\begin{array}{l}\text { contraindicated for } \\
\text { neonatal use }\end{array}$ & $14(3.8 \%)$ & $\begin{array}{l}\text { Unauthorized for neonatal } \\
\text { use }\end{array}$ \\
\hline Cefotaxime & 17 & $13(3.57 \%)$ & Dose too high & & \\
\hline Phenobarbital Tablet & 10 & $10(2.75 \%)$ & $\begin{array}{l}\text { Unauthorized dosage form } \\
\text { for age }\end{array}$ & $10(2.8 \%)$ & $\begin{array}{l}\text { Lack of suitable dosage } \\
\text { form }\end{array}$ \\
\hline Aminophylline injection & 7 & $7(1.92 \%)$ & $\begin{array}{l}\text { contraindicated for } \\
\text { neonatal use }\end{array}$ & $7(1.9 \%)$ & $\begin{array}{l}\text { Unauthorized for neonatal } \\
\text { use }\end{array}$ \\
\hline Vitamin $\mathrm{K}$ & 6 & $5(1.38 \%)$ & Dose too high & & \\
\hline Furosemide Tablet & 5 & $5(1.37 \%)$ & Dose too high & $5(1.4 \%)$ & $\begin{array}{l}\text { Lack of suitable dosage } \\
\text { form }\end{array}$ \\
\hline Gentamycin & 84 & $5(1.37 \%)$ & Dose too high & & \\
\hline Others & 44 & $28(7.69 \%)$ & Different reason & $27(7.4 \%)$ & Different reason \\
\hline Total & 364 & $246(67.58 \%)$ & & $86(23.6 \%)$ & \\
\hline
\end{tabular}

Regarding unlicensed medicine use, $46.7 \%$ of the neonates were exposed to at least one unlicensed medicine. Of the total (364) prescribed medicines only $23.63 \%$ of them were unlicensed for neonatal use. This is higher compared to reports of many studies conducted elsewhere which reported unlicensed medicine use in the range of $1.9-19 \%[3,11,13,22,23]$. However, lower compared to a study done in India in which $56 \%$ of the prescriptions were unlicensed for neonatal use [4]. The difference might be related to the differences in medicines licensing policy across the countries, disease pattern difference or differences in definitions of unlicensed medicines used in the other studies.

The use of off-label and unlicensed medicines was found to differ by the gestational age of the neonates. Many studies elsewhere in the world reported high rate of off-label [11, 12, 22, 24] and unlicensed [11] medicine use among pre-term neonates. Despite the number of post-term neonate were very small in our study, off-label prescriptions were relatively higher for post-term and preterm neonates where $(8 / 8)$ and $(43 / 45)$ of the postterm and pre-term neonates were exposed to at least one off-label medicines respectively. Similarly post-term and pre-term neonates were also found to be exposed to unlicensed medicines at higher rate where $(5,62.5 \%)$ and $(22,48.9 \%)$ of the post-term and pre-term neonates were exposed to at least one unlicensed medicines respectively. The high number of off-label and unlicensed medicine use in post-term and preterm neonates in the present study might be related with scarcity of medicines that are suitable for use in the mentioned neonatal categories.

In the present study, antibiotics were the most commonly used off-label medicines compared to the other classes of medicines. This was similar finding with that of study reports from Iran and Italy [3, 24]. However, it was different from a study conducted in Netherlands which reported that blood products were the top class of medicines used in an off-label manner [20]. The difference might be related with difference in disease status. On the other hand, antibiotics were also found to be the most commonly prescribed medicines in unlicensed manner in our study. This was in consistence with a study finding from Iran [3]. But studies from southern Italy and Irish neonatology reported caffeine as the most commonly used medicine in an off-label manner. This can be explained by differences in disease epidemiology across the study settings.

The most commonly prescribed off-label medicine was ampicillin 99(27.2\%) followed by Vancomycin 23(6.33\%) and Ceftazidim 21(5.77\%). The main reason for the offlabel use of medicines were lack of neonatal use information's, and dose higher than the recommended. The same reason was also reported from a study conducted in Iran [3]. However our finding were different from studies conducted in Germany, Brazil and India which reported the commonest reason for being off-label as frequency of administration, dosage form difference, and dose respectively $[4,9,13]$. This is expected since such difference might be atributed to differences in medicines 
licensing policy across the countries, disease pattern difference or difference in definitions of off-label medicines used. Paracetamol, phenobarbital, and aminophylline were the most commonly used unlicensed medicines due to their lack of neonatal use information and inappropriate dosage forms for neonatl patients. The same resason was cited from a study done in India [4].

As a limitation, the study was conducted in small number of study participants for short period of time in a single center; thus further study is needed to strengthen the generalizability of this evidence. In addition, the data was collected from patients' medical records and prescriptions; therefore, reason for off-label and unlicensed use and the possible harmful side effects of this off-label/unlicensed use were beyond the scope of this study.

\section{Conclusion}

Off-label and unlicensed medicine prescriptions are very common among neonates admitted to intensive care unit of ACSH. Selecting and identifying the safest medicines for these vulnerable patients is necessary to promote rational prescribing and better therapeutic benefit.

\section{Abbreviations}

ACSH: Ayder Comprehensive Specialized Hospital; ADR: Adverse Drug

Reaction; NICU: Intensive Care Unit

\section{Acknowledgments}

The authors would like to acknowledge the hospital administration and the staff working in the ICU for their support and relevant inputs for the study accomplishment.

\section{Authors' contributions}

MTG conceived, designed and analyzed the result and participated in the manuscript write up; YG supervised the data collection, participated in the data entry analysis and manuscript write up, AGT, AGW and BTA participated in the design, analysis and manuscript writing. All authors read and approved the manuscript.

\section{Funding}

No funding was received.

\section{Availability of data and materials}

All datasets from which we derived our conclusion is deposited in SPSS software and it can be accessed from the corresponding author on reasonable request.

\section{Ethics approval and consent to participate}

The study was conducted after ethical approval from the Ethics Review College of health sciences, Mekelle University. An official support letter was granted from the hospital administration.

\section{Consent for publication}

Not applicable.

\section{Competing interests}

All authors declared that there is no competing interest.

\section{Author details}

${ }^{1}$ Pharmacoepidemiology and Social pharmacy Course and Research Unit, School of Pharmacy, College of Health Sciences, Mekelle University, Mekelle, Ethiopia. ${ }^{2}$ Department of Clinical Pharmacy School of Pharmacy, College of Health Sciences, Mekelle University, Mekelle, Ethiopia. ${ }^{3}$ Department of
Pharmacology and Toxicology, School of Pharmacy, College of Health Sciences, Mekelle University, Mekelle, Ethiopia.

Received: 23 November 2019 Accepted: 25 March 2020

Published online: 03 April 2020

\section{References}

1. Palcevski G, Skocibusic N, Vlahovic-Palcevski V. Unlicensed and off-label drug use in hospitalized children in Croatia: a cross-sectional survey. Eur J Clin Pharmacol. 2012;68(7):1073-7.

2. Saiyed MM, Lalwani T, Rana D. Off-label medicine use in pediatric inpatients: a prospective observational study at a tertiary care hospital in India. Int J Pediatr. 2014:2014:415815

3. Kouti L, Aletayeb M, Aletayeb SMH, Hardani AK, Eslami K. Pattern and extent of off-label and unlicensed drug use in neonatal intensive care units in Iran. BMC Pediatr. 2019;19(1):3.

4. Jain S, Saini SS, Kumar P, Dhir S. Off-label use of drugs in neonatal intensive care units. Indian Pediatr. 2014;51(1):644-6.

5. Silva J, Flor-De-Lima F, Soares H, Guimraes H. Off-label and unlicensed drug use in neonatology: reality in a Portuguese University hospital. Acta Medica Port. 2015;28(3):297-306.

6. Dell'Aera M, Gasbarro AR, Padovano M, Laforgia N, Capodiferro D, Solarino B, Quaranta R, Dell'Erba AS. Unlicensed and off-label use of medicines at a neonatology clinic in Italy. Pharm World Sci. 2007;29(4):361-7.

7. Cuzzolin L, Zaccaron A, Fanos V. Unlicensed and off-label uses of drugs in paediatrics: a review of the literature. Fundam Clin Pharmacol. 2003;17(1): 125-31.

8. Lindell-Osuagwu L, Korhonen M, Saano S, Helin-Tanninen M, Naaranlahti T, Kokki H. Off-label and unlicensed drug prescribing in three paediatric wards in Finland and review of the international literature. J Clin Pharm Ther. 2009; 34(3):277-87.

9. Neubert A, Lukas K, Leis T, Dormann H, Brune K, Rascher W. Drug utilization on a preterm and neonatal intensive care unit in Germany: a prospective, cohort-based analysis. Eur J Clin Pharmacol. 2010;66(1):88-95.

10. Dos Santos L, Heineck I. Drug utilization study in pediatric prescriptions of a university hospital in southern Brazil: off-label, unlicensed and high-alert medications. Farm Hosp. 2012;36(4):180-6.

11. Kieran EA, O'Callaghan N, O'Donnell CP. Unlicensed and off-label drug use in an Irish neonatal intensive care unit: a prospective cohort study. Acta Paediatr. 2014;103(4):e139-42.

12. de Souza AS Jr, Dos Santos DB, Rey LC, Medeiros MG, Vieira MG, Coelho HLL. Off-label use and harmful potential of drugs in a NICU in Brazil: a descriptive study. BMC Pediatr. 2016;16:13.

13. Gonçalves ACS, Reis AMM, Marçal ACG, Bouzada MCF. Use of unlicensed and off-label drugs in neonates in a Brazilian university hospital. Braz J Pharm Sci. 2018:53(3):e00252.

14. Costa H, Costa TX, Martins RR, Oliveira AG. Use of off-label and unlicensed medicines in neonatal intensive care. PLoS One. 2018;13(9):e0204427.

15. Laforgia N, Nuccio MM, Schettini F, Dell'Aera M, Gasbarro AR, Dell'Erba A, Solarino B. Off-label and unlicensed drug use among neonatal intensive care units in southern Italy. Pediatr Int. 2014;56(1):57-9.

16. Arocas Casan V, Cabezuelo Escribano B, Garrido-Corro B, De la Cruz MP, Blazquez Alvarez MJ, De la Rubia Nieto M. Off-label and unlicensed drug use in a Spanish neonatal intensive care unit. Farm Hosp. 2017;41(3):371-81.

17. Tefera YG, Gebresillassie BM, Mekuria AB, Abebe TB, Erku DA, Seid N, Beshir HB. Off-label drug use in hospitalized children: a prospective observational study at Gondar University Referral Hospital, Northwestern Ethiopia. Pharmacol Res Perspect. 2017;5(2):e00304.

18. Sado E, Sufa A. Availability and affordability of essential medicines for children in the Western part of Ethiopia: implication for access. BMC Pediatr. 2016;16(1):40.

19. AAPC. Advancing the Business of health care, ICD-Coding forum. https:// www.aapc.com/discuss/threads/post-term-pregnancy-dx.150197/. Accessed on 16 Mar 2019.

20. Flint RB, van Beek F, Andriessen P, Zimmermann L, Liem KD, Reiss IK, de Groot R, Tibboel D, Burger DM, Simons SH. Large differences in neonatal drug use between NICUs are common practice: time for consensus? $\mathrm{Br}$ J Clin Pharmacol. 2018:84(6):1313-23.

21. Aamir M, Khan JA, Shakeel F, Shareef R, Shah N. Drug utilization in neonatal setting of Pakistan: focus on unlicensed and off label drug prescribing. BMC Pediatr. 2018;18(1):242 
22. Carvalho CG, Ribeiro MR, Bonilha MM, Fernandes M Jr, Procianoy RS, Silveira RC. Use of off-label and unlicensed drugs in the neonatal intensive care unit and its association with severity scores. J Pediatr. 2012;88(6):465-70.

23. O'Donnell CP, Stone RJ, Morley CJ. Unlicensed and off-label drug use in an Australian neonatal intensive care unit. Pediatrics. 2002;110(5):e52.

24. Girardi A, Galletti S, Raschi E, Koci A, Poluzzi E, Faldella G, De Ponti F. Pattern of drug use among preterm neonates: results from an Italian neonatal intensive care unit. Ital J Pediatr. 2017:43(1):37.

\section{Publisher's Note}

Springer Nature remains neutral with regard to jurisdictional claims in published maps and institutional affiliations.

Ready to submit your research? Choose BMC and benefit from:

- fast, convenient online submission

- thorough peer review by experienced researchers in your field

- rapid publication on acceptance

- support for research data, including large and complex data types

- gold Open Access which fosters wider collaboration and increased citations

- maximum visibility for your research: over $100 \mathrm{M}$ website views per year

At $\mathrm{BMC}$, research is always in progress.

Learn more biomedcentral.com/submissions 